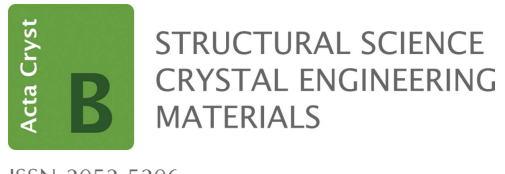

ISSN 2052-5206

\title{
Pyrite. A Natural History of Fool's Gold. By David Rickard. Oxford University Press, 2015. Hardback, XIX+297 pages, 4 colour plates. Price GBP 20.49. ISBN 9780190203672.
}

\author{
Massimo Nespolo* \\ Université de Lorraine, CRM2, UMR 7036, Vandoeuvre-les-Nancy, F-54506, France, and CNRS, CRM2, UMR 7036, \\ Vandoeuvre-les-Nancy, F-54506, France. *Correspondence e-mail: massimo.nespolo@crm2.uhp-nancy.fr
}

Keywords: book review; fool's gold; pyrite.

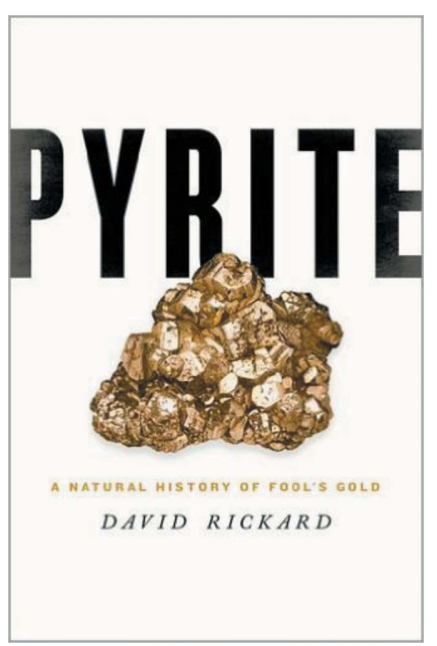

C 2016 International Union of Crystallography
Almost three centuries have passed since Henckel's monumental work on pyrite (Henckel, 1725, 1757). The new book by David Rickard, world authority on sulfide chemistry, geochemistry, geomicrobiology, biogeochemistry and ore geology, is a most welcome state-of-the-art report about this humble but fascinating mineral.

As stated in the preface, the book targets a popular rather than an academic audience; the latter is referred to the impressive research monograph on sulfides published three years before (Rickard, 2012). Nevertheless, a wide-ranging basic education spanning from chemistry to physics, from geology to biology, is necessary to get the most from this comprehensive text in which the author has summarized an impressive amount of data and knowledge.

The preface is followed by a prologue, which sets the landscape where pyrite will be hunted in all its aspects in the ten chapters which compose the book. Each chapter is complemented by a series of notes that go beyond the simple bibliography. The journey ends with an epilogue, followed by an extensive (17 pages) index. The book also includes the colour versions of 16 figures printed as four colour plates just before page 203.

As clearly stated in the Prologue, this book aims at demonstrating a thesis: pyrite has accompanied and even shaped our civilization since its beginning, not only in the extractive metallurgy, to recover the various metal impurities, but also for its use as a source of sulfur for the black powder (army industry) and of sulfuric acid used in chemicals (e.g. fertilisers), the textile industry (vitriols used as mordants) and pharmaceuticals (alums). It has even contributed to the evolution of early life, as described by the iron-sulfur world model (Wächtershäuser, 1992); it keeps providing us with fundamental pieces of information about the history of the Earth and can be used to predict the future changes in the environment, noting that human activity has increased the rate of pyrite oxidation, making the environment more acidic. These may overall sound like overstatements, but the journey in the sulfidic ocean that the reader undertakes by opening this book should convince him of the primary role played by this mineral in the major events of our planet.

The analysis is really a $360^{\circ}$ approach, including an historical analysis of pyrite nickname 'Foole's Gold' (the archaic spelling emphasizing the ancient root of this naming) that dates back to the false attribution of pyrite crystals as gold already at the time of the Sumerian civilization. More recently, this same confusion led to the first European settlement in the New World, which was established precisely in the quest for gold, which turned out to be pyrite. This historical approach is complemented by detailed philological analyses - which include the reasons why sulfur has changed to sulfur - of the Sumerian, Arabic, Akkadian, Persian, Greek and Chinese names. The origin of the name pyrite is traced back to the clay tablets produced by the Sumerians and emphasis is put on the long confusion with the term marcasite, often used in jewellery to indicate pyrite, but which indicates the polymorph (actually, polytype) metastable at ambient conditions. We learn that up to Henckel $(1725,1757)$ the presence of iron escaped to most investigators, even Agricola mentioning an ore of sulfur and 'stone'. The alchemical description is taken only in its literal meaning, and thus obviously severely criticized, ignoring its role of secret language under which ancestral esoteric practices were hidden to escape the Catholic repression (Evola, 1931, 1999). 
The origin of pyrite has long puzzled mankind. A comprehensive analysis of the various hypotheses is presented here, which spans the Bible, Aristotle and the Alchemists, up to contemporary oceanographic research that revealed massive pyrite deposits in black smokers - the deep-ocean hydrothermal vents typical of abyssal zones. We learn about the role pyrite has played in the so-called chemical theory of the origin of Earth internal heat, which for centuries was considered originating from exothermic reactions, a theory based on the exothermic oxidation of pyrite when it comes in contact with oxygen.

Crystallographers' interest certainly reaches its zenith when 'crystals and atoms' appear in Chapter 4 (the International Year of Crystallography is mentioned in a previous chapter), where a reproduction of Henckel's classification of pyrite habits gives the reader an idea of the variability in pyrite morphology. This is followed by a presentation on the atomic structure of pyrite and experimental techniques to determine it, and a discussion about the predominance of cube over octahedron and pentagon-dodecahedron, with emphasis on the origin of the striated cubic faces, where the alternate occurrence of small holohedral (cubic) and hemihedral (pentagon-dodecahedron) faces suggests the hemihedral nature of the crystal structure. Probably less commonly known to non-specialists is the very large diffusion of pyrite framboids with icosahedral arrangement of pyrite microcrystals: this arrangement is known to minimize energy in case of small clusters (Senechal, 2015).

A large space is devoted to the microbiological origin of most pyrite on Earth, which is possibly less well known by the general audience, partly because of the common but incorrect idea relating pyrite to volcanism, which actually plays only a minor role. The topic is introduced by first emphasizing the abundance of sedimentary pyrite. The action of sulfate-reducing bacteria in sediments produce hydrogen sulfide, largely reoxidized to sulfate by sulfur-oxidizing bacteria. The hydrogen sulfide remaining, which is extremely poisonous, reacts with iron salts to produce pyrite, whose presence is responsible for colour of the so-called blue muds: the mineral thus acts as a safety valve against the escape of the gas into the oceans. Iron is, however, a limiting element in this equilibrium and excess production of $\mathrm{H}_{2} \mathrm{~S}$ eventually results in euxinic conditions, where the gas occurs in seawater, not only in sediments. The outcome is the occurrence of the so-called dead zones, where higher animals cannot live, which are becoming widespread because of the global warming of the planet. These events occurred several times in the Earth's history, were accompanied by mass extinctions and are recorded as increase of iron in sediments in the form of pyrite.

The consequences of the bacterial origin of pyrite are farreaching and unlock a scenario which leads the reader to a journey back to the early Earth. The bacterial origin leaves an isotopic signature in pyrite in the form of an abundance of lighter sulfur isotopes with respect to the sulfate from which it originates, allowing us to distinguish it from pyrite of nonbiological origin, which lack this signature. A discontinuity in the sulfur isotopic ratio in sedimentary pyrites with respect to sedimentary rocks older than 2.5 billion years places the switch from anoxic to oxic conditions in the Earth's atmosphere a few hundred million years earlier than previous estimations (Rutten, 1962). Pyrites also bring information that go from beyond our planet: its presence in some rare Martian meteorites (meteorites normally contain troilite, FeS) points at the presence of water on Mars about 4 billion years ago.

A role for pyrite is advocated also to explain the origin of life. It is not the first time that a mineralogical origin of biological molecules capable of self reproducing is proposed: the role of clays had been advocated before by one of the fathers of modern crystallography (Bernal, 1949). Here the attention is focused on the possible rôle of pyrite as a catalyst in the synthesis of DNA precursors around 3.85 billion years ago, in the presence of water and with life-compatible temperature, as shown by the isotopic compositions of gases trapped in mineral impurities in the pyrite from Greenland sediments. From there, a detailed analysis of the experimental evidence of this hypothesis is presented, with an interdisciplinary approach spanning from geology to (micro)biology which requires some effort to gain a full understanding not only for the general public, the declared target audience of this book, but also by a reader with a more scientific background.

Another important topic addressed in depth concerns the environmental effects of the oxidation of pyrite when exposed to the atmosphere. Release of sulfuric acid and leaching of pollutant metals and semi-metals from tailings are among the environmental hazards oposed by abandoned mines. However, mining of pyrite itself is not the only reason for its exposure to oxidation. Coal mining exposes co-existing pyrite, whose oxidation is responsible for coal ignition, often resulting in the so-called eternal fires: once started, these cannot be extinguished and continue to burn for years, sometimes for centuries, with a catastrophic environmental impact. Release of sulfur dioxide in the environment from pyrite oxidation comes also from burning in power stations of pyrite present in coal, which leads to acid rains and smog formation; although not the target of the book, the role of other pollutants present in coal, in particular fluorine (Waldbott, 1974), could well have been mentioned. Sulfuric acid from oxidized pyrite is also at the root of the so-called mundic problem, the deterioration and mechanical weakening of the buildings constructed from concrete blocks which contain pyrite. But pyrite oxidation is not only due to anthropogenic causes: when pyrite reacts with water, extensive production of free radicals occurs, which could have been at the root of mass extinctions of microbial species over large geological intervals.

The text was obviously carefully proof-read and very few typos remains, concentrated at page 99 . When counting the number of atoms in a $1 \mathrm{~cm}$ cube of pyrite, ' 250 quintillian' should be '250 quintillions' and '50 quintillian' should be '500 quintillions'. Also, a word seems missing in the sentence 'electronic signals in the received [what?] from the probe'. A mistake occurs at endnote 12 on page 114, which states that 'the pyritohedron [i.e. pentagon-dodecahedron] has only twofold symmetry whereas all the rest of the cubic forms have 
fourfold symmetry': this is obviously untrue, because also the tetartoid and the diploid, which are cubic forms, lack fourfold rotations in their eigensymmetry (Nespolo, 2015). Endnote 15 on page 115 contains a curious mistake where $360 / 5$ is said to be equal to 108 (exterior angle) rather than 72 (interior angle).

The amount of information enshrined in this book is impressive. Conceived to target the general audience, the presentation may sometimes appear less satisfactory for a scientist in that closely related topics are spread through different chapters. For example, the role of bacteria could have been used as a common denominator to gather at least some of the material distributed in Chapters 6 ('Microbes and minerals'), 7 ('Acid Earth'), 8 ('Pyrite and global environment'), 9 ('Pyrite and the origin of life') and 10 ('Full circle') and made the reviewer's task easier. But keeping in mind the audience, the strategy chosen does indeed make sense.

In conclusion, this is a fascinating book that contains much more of what can be squeezed in a short review like this. It will certainly reveal a whole unexpected world to the general audience and serve as an appetizer for those with a solid scientific background: the main course being obviously the extensive monograph by the same author (Rickard, 2012).

\section{References}

Bernal, J. D. (1949). Proc. Phys. Soc. A, 62, 537-558.

Evola, J. (1931). La tradizione ermetica nei suoi simboli, nella sua dottrina e nella sua 'arte regia'. Bari: Laterza.

Evola, J. (1999). The Hermetic Tradition: Symbols \& Teachings of the Royal Art. Rochester: Inner Traditions International.

Henckel, J. F. (1725). Pyritologia: oder: Kieß-Historie, als des vornehmsten Minerals nach dessn Nahmen, Arten, Lagerstätten, Ursprung. Leipzig, Verlegts Johann Christian Martini, 1008 pp.

Henckel, J. F. (1757). Pyritologia: Or, A History Of The Pyrites, the Principal Body in the Mineral Kingdom. London: Millar \& Linde. Nespolo, M. (2015). J. Appl. Cryst. 48, 1290-1298.

Rickard, D. (2012). Sulfidic Sediments and Sedimentary Rocks, IX+801 pp. Amsterdam: Elsevier.

Rutten, M.G. (1962). The geological aspects of the origin of life on Earth, VII+146 pp. Amsterdam, New York: Elsevier.

Senechal, M. (2015). Z. Kristallogr. 230, 691-698.

Wächtershäuser, G. (1992). Prog. Biophys. Mol. Biol. 58, 85-201.

Waldbott, G. L. (1974). Fluoride, 7, 174-176. 